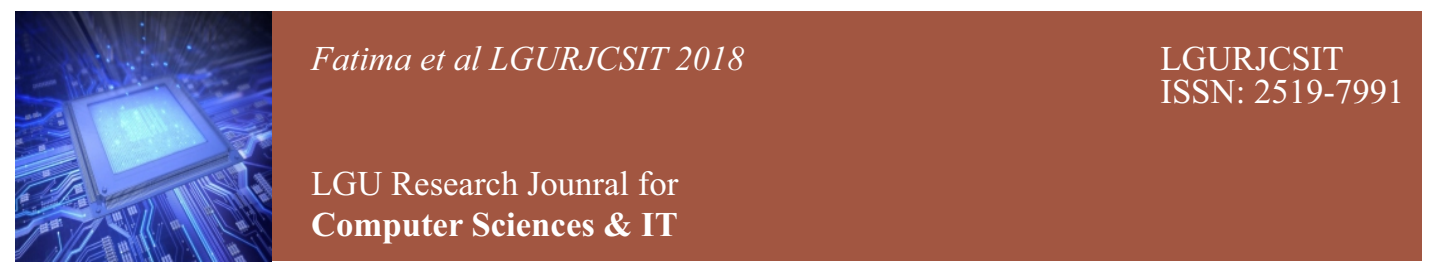

\title{
Cloud Based Intelligent Decision Support System for Disaster Management Using Fuzzy Logic \\ Areej Fatima, ${ }^{1}$, Sagheer Abbas ${ }^{2}$, Muhammad Asif ${ }^{2}$ \\ 'Department of Computer Science LGU Lahore, Pakistan areejfatima@lgu.edu.pk \\ ${ }^{2}$ Department of Computer Science NCBA\&E Lahore, Pakistan Muahmmadasif@ncbae.edu.pk
}

\section{Abstract:}

Field of cloud computing is an emerging field in computer science. Computational intelligence and Decisions Supports Systems (DSS) have to gained concerns as a computing solution to planned and unplanned problems of organizations in order to progress decision-making tasks in a better way. In today era, Disaster management is a big problem. To overcome this problem, a real time computation is required. Cloud computing is a tool to offer promising support to decision support system in a real time environment. In this paper, a fuzzy based decision support system is proposed to meet all the requirements using fuzzy logic inference system.

\section{Keywords}

Disaster management, decision support system, cloud computing.

\section{INTRODUCTION}

Cloud computing is composed of list of Information Technology services provided to users over network by the third-party vendors. Services of cloud computing are provided on network as "as a service" i.e. Software as a Service (SaaS), Platform as a Service (PaaS), Infrastructure as a Service (IaaS). Cloud computing is a very comprehensive perception of infrastructure convergence. [2] These huge services allow users such as Enterprises to get their application up and running from remote place in more convenient way and allow them to manipulate it in more efficient way and meet the growing demand of business. Concept of cloud computing can be understood easily with the example of Play Store for Android and iTunes for Apple. All the application of such devices like smart phones and tablets, can be stored and managed on one place. [1]

Cloud environment have solved many problems like storage problem, problem of large memory space at user-end is solved due to the cloud services. Users can store his data over cloud storage in case of data loss or damage device he/she can easily get that data. Computing tendencies like grid computing,
"Pay as you go use" distributed computing; vitalization show that cloud computing is a multi-disciplinary research field. Actually, lattice computing has evolved into businessoriented form as cloud computing. Cloud computing has brought a marked change in business and IT infrastructure, everywhere computing power, large data storage and other services are subcontracted to third. Cloud computing is a technology and computing model. It provides timely, on-demand network access to the common pool of configurable computing properties. [5]

In 2012 IBM have provided a global private cloud for French Open Tennis tournament. This cloud service was developed to fulfill demands, like real-time score, statistics as well as video clips of tournament, of increasing number of fans. These services can be accessed through it. Cloud computing is a dispersed computing platform. It needs a medium through which it may share the resources, these resources comprise the data that play a vital role for (DSS) Decision support systems. [6]

Cloud computation have four major designs which are: 
- Private Cloud.

- Hosted Private Cloud.

- Public Cloud.

- Hybrid Cloud.

Cloud application can be accessed by using web browsers, desktop and mobile application. Organizations using mobile applications, big data or with multiple locations can benefit from a cloud at a large scale by deploying cloud services.

Irvine (2012) elucidate a private cloud as technology "hosted and managed on-premises by the client, usually behind a firewall, and access to cloud services is exclusive to that client." The major change for a hosted private cloud is that the technology is "hosted offpremises and managed by a cloud service provider, but access to cloud services is exclusive to one client". A public external cloud is hosted and also managed by a cloud service provider, such that multiple clients have access. [13]

The National Institute of Standards and Technology connote Web, smart phones and tablets such as the I Pad." An excellent design cloud that uses unusual, may be suitable for reliable, secure and commercial applications. Effective use of cloud to provide support can not only reduce winter costs, but also practical costs (Ari, 2002). According to Jackson (2011), "proper implementation can provide adequate savings, IT services and advanced credentials". It is claimed that other benefits are agility, software and device accessibility, as well as freedom of space. In short, benefits include:

Greater reliability: A DSS is always available where it is required.

More secure: Appropriate usage of shields brings about a framework that is less inclined to physical and digital (cyber) assaults

- Pitch-perfect for distributed business operations.

- Decrease capital overheads

- Reduce operational cost.

- Have the capacity to support new decision system.

- Have access from all over the world.

- Available on multiple devices at a time.
- Has the capacity to expansion and minimization?

- Has the capacity to take backup remotely. For example, support systems can be considered better. Consider that a user goes to the train. As soon as you are a train board, you can change the conditions of environmental computing. If the tunnel enters the entrance, the user's connectivity may be at the moment; the train leaves the tunnel when the connection restarts. But with a Decision Support System (DSS) user can adjust their relationship with the DSS as soon as he knows the tuning is approaching or to use the system in such a way. It plans to prevent it from being completely obstructed. Downloading data and communicating locally. It may be possible that time and distance of intervention cannot be accurately calculated, but at times it may be possible for a period of time and possession. The UN has described destruction as a society or an error in the society. Disasters include human, material, economic or environmental effects, to cope with their own resources more than the impact of the affected community or society.

Red Cross society and Red Crescent Society described demolition management as resource management and responsibilities, such as solutions to all human aspects of emergency, especially reducing the effects of preparation, response and maintenance.

There is no disaster in the country that is causing trouble. There are four main types of disasters.

Natural disasters: The effects of flood, storm, earthquakes and erosion have direct effect on human effects and minor effects that cause decease and trouble over flood, earthquake, fire and tsunami.

Environmental emergency conditions: including technical or industrialized accidents, which may include the production, practice or transport of dangerous materials, and in the event where these materials are manufactured, cast-off or copied and the jungle fire triggered by humans.

Complex disorders: including conflicts and war conditions, authority on strategic facilities, looting and eliminating attacks.

Pandemic emergencies: A sudden appearance of a deadly disease that affects health, services and business intervention, they 
have a large economic and social value.

Any adversity can impose on basic managements, for example, community protection, supremacy, water, manure/junk removal, transportation and interchanges. The intrusion can seriously influence the well being, social and financial network of local groups and nations. Disasters have a major and long-lasting impact on people long after the immediate effect has been mitigated.

\section{Disaster prevention}

These activities are planned and offer everlasting security against the adversities. Some natural calamities can be clogged, but the threat to life and wood defeat can be reduced with decent transition planning, eco friendly formation and scheme values, but not all the disasters. In Jan 2005, the Administrations provided a 10 -year worldwide plan to $168 \mathrm{Hugo}$ Framework to eliminate the natural hazard's risk reduction. It offers priorities for recipe rules, actions and practical resources to get the flexibility for the disaster for a dangerous community.

\section{Disaster preparation}

This type of activities is designed to design that minimize the damage by eliminating people and loss of life and property and timely and effective rescue, relief and healing from the threatened place. An important way of preparing to reduce the effects of disasters. For the management process, the preparation and management of people's groups in physiotherapy should be high priority.

\section{Disaster relief}

It is a coordinated response by many agencies to decrease the impact of a disaster and its long-term consequences. Respite actions comprise of saving, transfer, diet and water supply, prevention of diseases and disabilities, key facilities such as communications and transportation, housing supplies and extra medical care.

\section{Disaster Maintenance}

Once emergency needs can be met and the initial crisis is over, people are affected and the support of those communities remains weak.
Maintenance activities include construction of basic infrastructure, medical care and maintenance. These development activities, such as the creation of human resources for health and future development, should be combined with the development of policies and practices.

Disaster management is associated with sustainable development, especially with dangerous people. Foreign volunteers abroad talked about common misconceptions about disaster management.

Recent disasters have crashed destruction on human population and infrastructure, the cost of maintenance is much higher after such a disaster. Storm Ocean and Tsunami in the Ocean are examples of such disasters. Such disasters affect life, wound and spread of waste in large areas. In some cases, it was possible to see the events that occurred in real time. Satellite photos taken from these sites are used to use digital maps to monitor harmful reviews and monitor the guidance of efforts to restore digital land applications. However, research needs to be made to improve many key issues in this regard and these tools and tools of tools and geo spatial have certainly produced some results, but they do not agree with their expectations. The media plays an important role in mobilizing relief efforts by informing people related to the affected area.

Fuzzy Logic provides resources through the audible to test the environment in the cloud. The fuzzy logic parameter eliminated by the user, which was introduced for RAM, disk storage, and system traffic. Cloud performance analysis is calculated using logical and fuzzy rules. It explains how different values of the given parameters can develop cloud performance or drop-down.

In many cases, people living far away from the affected area have been better informed by media compared to those who manage and manage relief efforts. The affected area deprives the power, Internet connectivity and computer skills that prevent information flow. A recent report of the US National Research Council. One Yu (NCRC) 2007 stabilized the issues, based on broad discussion with respondents and emergency managers, improving the situation and making a series of recommendations for necessary research. 


\section{LITERATURE REVIEW}

After taking into the support framework for the consumers, new technical tips should be developed. In recent days, cloud computing has become a paragraph which can be used for emergency professionals [2]. The main objective of improving this technology is to increase the capacity of individual computer technology, which is useful for urgent emergency support. Support system for decision making can be extended to train the emergency professionals, health officials and workers, natural disaster workers and other relevant professionals [1, 8-9].

United Nations report about the end of the disaster resulting in the destruction of Japan, in which was claimed that 85,541 people per year affected 230 million people per year. For the 2005-2015 action, the Virtual Study of The Hague Framework is an annual climate related to climate, about $50 \%$ more than $50 \%$ over 2015 , about 2015 Is affected with the passing of government and non-government levels, demand for working on joint-day disasters is increasing to meet together [3-4]. Accidents related to seasonal changes require immediate response of officials. Public and public organizations need joint efforts to form health teams, civil security, fire and saving services, basic health amenities to protect the human community and their structure. A real-time analysis of the situation requires to make and operate effective decisions.

Judgement making is not compulsory to pre-post and post emergency. Wherever there is a need for exchange of information during the emergency; however, it may be very diverse and complicated. It is believed that there are some communities that do not have resources, personal and skill, to help manage activities to develop a specific need to help them from this disaster.

Due to the decent and extraordinary nature of destructive situations, various emergency approaches are not enough. The right information and intellectual resources are accurate in accurate time. Many ICT-based mutual-mutual-co-ordination systems have been developed to share e-mail [11-13]. Such measures are instantly administering any destructive situation but cannot meet the demands. Someone may have reason to take real-time situations for any project or alternative decision, as well as concrete and compact realtime information can be obtained [5-6]. Pinokova et al. presented a view of integrated data storage using the operational control of the technical sector and environmental items [7].

Lee et al. reviewed the system of information management in mass destruction for the public. It has suggested that the proposed techniques are not applicable to a very unstable complex disaster environment, which requires immediate answers to a large number of large organizations [10].

Yang Lu explained how to participate in the exchange of information in the social winter virtual community. It analyzes online social networks and proposes social technical design rules to meet communication challenges under uncertain emergency.

\section{METHODOLOGY}

Here we have proposed a cloud-based model that you set up intelligent decisionmakers system to manage destruction by using fuzzy logic based on fuzzy logic decisions (between 0 and 1), no decision between 0 and 1 should be done. Emergency or destructive hours. All actions or ingredients are connected to the cloud (DSS). 1ST components are emergency professionals and local assistant agents on the site. The second internal administration and the government's decision-making. Third resource information all that depends on the cloud-based (DSS).

\subsection{Proposed model}

The proposed decision system is based on system cloud technology. The proposed decision support system (DSS) is an instrument that has managed to attract the attention of many current research studies, which applies by the various artificial techniques aimed at goals. DSS is based on cloud computing using Fuzzy Logic. There are three dimensions to form and distribute the decision-making system. Regarding the cloud-based (DSS) IP and LSA emergency situation, for example, identify the need for cooperation (BOM). The right-side box 
defines the involvement of admission in various operations, for example, and identifies local audience or death if they access the basic system of instant messages or warning signals. Official manager's box is right to manage the management. This means dimension resources to establish and make complicated decisions for planning plans.

Finally, emergency professionals on the left are important agents who need access to all the information supporting various information. This decision-making service is necessary for relevant stock holder groups, because they are directly related to action-making activities. The internal management of the information can be accessible with emergency updates for emergency professionals, with the latest updates for the latest information and process decision.

The main use of fuzzy suggestion that is for problem solving, provide us relationship for measurement and logics. Fuzzy suggestion has ability to hold and in perfect inputs. This module has three major components.

a) Inference Engine: By the inference Engine that technically handles the unclearness of the program.

B) Membership functions: Using this function of fuzzy deals that belongs to the analogous it extends fuzzy elements.

b) Rule Base: It is a set of all rules which can be made on the basis of interface model theory also define this that depends upon the structure of the rules "if parameter of cloud is found then at what place does it exist" The inference process typically involves these five main steps:

Fuzzification: This step real fuzzy scalar value converts into fuzzy value. This is completed with different membership functions.

Applying fuzzy operations: By using AND, OR operator it tries to achieve different relations.

Implication: firstly, define the implication operator then obtain the set using fuzzy set by implementing all rules.

Aggregation: By using aggregation operator give output of fuzzy sets and all typical rules.

Defuzzification: Using defuzzification algorithm convert all aggregate fuzzy sets into cloud value to rank.

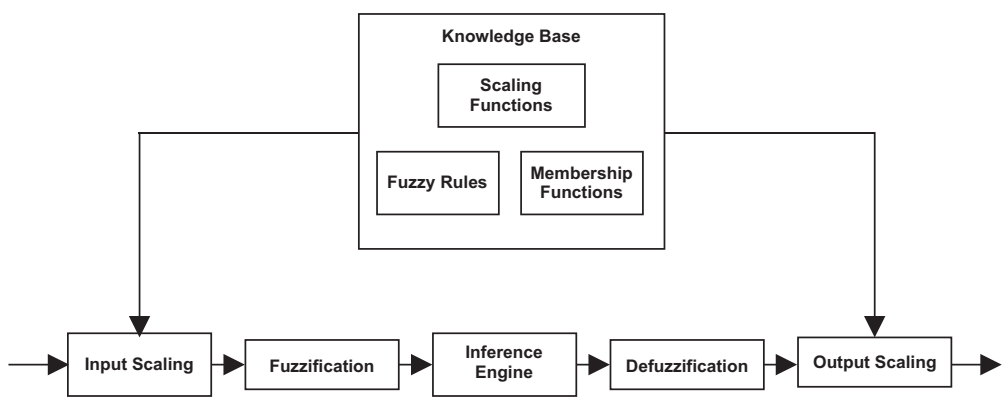

Figure 2: Proposed Fuzzy Based System

\subsubsection{Proposed Fuzzy based Disaster Management System}

There are three different parameters in the Decision Support System for a cloud service operator management through different resources. There are three other DSL parameters and local assistant agents, internal administration and government decision makers and information resources based on the local emergency cloud-based local site. The following tables show the range of functions and areas in three stages: Low, Medium and High. 
Table 1: EP and LSA

\begin{tabular}{|l|l|l|}
\hline Membership functions & Ranges & Regions \\
\hline Low & $1-55$ & 1 \\
\hline Medium & $1-100$ & $1-2$ \\
\hline High & $55-100$ & 2 \\
\hline
\end{tabular}

Table 2: IM and GDM

\begin{tabular}{|l|l|l|}
\hline Membership functions & Ranges & Regions \\
\hline Low & $1-55$ & 1 \\
\hline Medium & $1-100$ & $1-2$ \\
\hline High & $55-100$ & 2 \\
\hline
\end{tabular}

Table 3. Information resources (BOM)

\begin{tabular}{|l|l|l|}
\hline Membershipfunctions & Ranges & Regions \\
\hline Low & $1-55$ & 1 \\
\hline Medium & $1-100$ & $1-2$ \\
\hline High & $55-100$ & 2 \\
\hline
\end{tabular}

Table 4. Fuzzifier output and linguistic values

\begin{tabular}{|c|c|c|c|}
\hline Inputs & Linguistic outputs & Region1 & Region2 \\
\hline $\begin{array}{l}\text { emergency professional } \\
\text { onsite and local } \\
\text { supporting agent }\end{array}$ & $\begin{array}{l}\mathrm{m} 1 \\
\mathrm{~m} 2\end{array}$ & $\begin{array}{l}\mathrm{m} 1 \text { [1] } \\
\mathrm{m} 1 \text { [2] }\end{array}$ & $\begin{array}{l}\mathrm{m} 2 \\
\mathrm{~m} 2\end{array}$ \\
\hline $\begin{array}{c}\text { Internal management } \\
\text { and decision support } \\
\text { makers }\end{array}$ & $\begin{array}{l}\mathrm{m} 3 \\
\mathrm{~m} 4\end{array}$ & $\begin{array}{l}\mathrm{m} 3[1] \\
\mathrm{m} 3[2]\end{array}$ & $\begin{array}{l}\mathrm{m} 4[3] \\
\mathrm{m} 4[4]\end{array}$ \\
\hline Information resources & $\begin{array}{l}\mathrm{m} 5 \\
\mathrm{~m} 6\end{array}$ & $\begin{array}{l}\mathrm{m} 5 \text { [1] } \\
\mathrm{m} 5 \text { [2] }\end{array}$ & $\begin{array}{l}\mathrm{m} 6[3] \\
\mathrm{m} 6[4]\end{array}$ \\
\hline
\end{tabular}


Table 5: Input and Output Variables Membership Functions used in proposed model

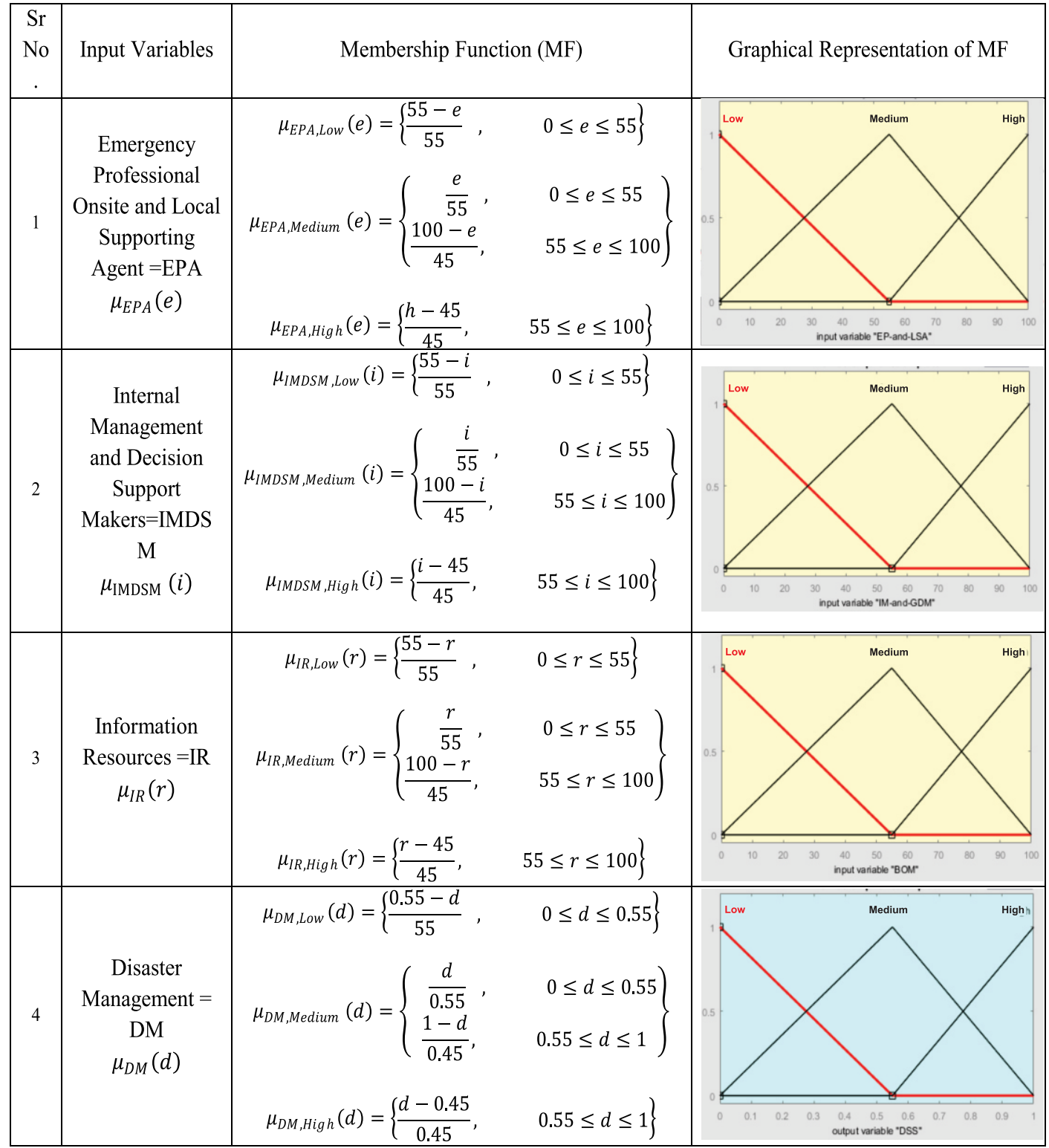




\begin{tabular}{|c|c|c|c|c|}
\hline \multicolumn{5}{|c|}{ Table 5: Look up table } \\
\hline Rules & $\begin{array}{c}\text { Emergency Professional Onsite and } \\
\text { Local Supporting Agent }\end{array}$ & $\begin{array}{l}\text { Internal Management and } \\
\text { Decision Support Makers }\end{array}$ & $\begin{array}{c}\text { Information } \\
\text { Resources }\end{array}$ & $\begin{array}{c}\text { Disaster } \\
\text { Management }\end{array}$ \\
\hline 1 & $\mathrm{~L}$ & $\mathrm{~L}$ & $\mathrm{~L}$ & $\mathrm{~L}$ \\
\hline 2 & $\mathrm{~L}$ & $\mathrm{~L}$ & $\mathrm{M}$ & $\mathrm{L}$ \\
\hline 3 & $\mathrm{~L}$ & $\mathrm{~L}$ & $\mathrm{H}$ & $\mathrm{L}$ \\
\hline 4 & $\mathrm{~L}$ & $\mathrm{M}$ & $\mathrm{L}$ & $\mathrm{L}$ \\
\hline 5 & $\mathrm{~L}$ & $\mathrm{M}$ & $\mathrm{M}$ & $\mathrm{L}$ \\
\hline 6 & $\mathrm{~L}$ & $\mathrm{M}$ & $\mathrm{H}$ & $\mathrm{M}$ \\
\hline 7 & $\mathrm{~L}$ & $\mathrm{H}$ & $\mathrm{L}$ & $\mathrm{L}$ \\
\hline 8 & $\mathrm{~L}$ & $\mathrm{H}$ & $\mathrm{M}$ & $\mathrm{M}$ \\
\hline 9 & $\mathrm{~L}$ & $\mathrm{H}$ & $\mathrm{G}$ & $\mathrm{M}$ \\
\hline 10 & M & $\mathrm{L}$ & $\mathrm{L}$ & $\mathrm{L}$ \\
\hline 11 & $\mathrm{M}$ & $\mathrm{L}$ & $\mathrm{M}$ & $\mathrm{M}$ \\
\hline 12 & $\mathrm{M}$ & $\mathrm{L}$ & G & $\mathrm{M}$ \\
\hline 13 & $\mathrm{M}$ & $\mathrm{M}$ & $\mathrm{L}$ & $\mathrm{M}$ \\
\hline 14 & $\mathrm{M}$ & $\mathrm{M}$ & $\mathrm{M}$ & $\mathrm{M}$ \\
\hline 15 & $\mathrm{M}$ & $\mathrm{M}$ & $\mathrm{H}$ & $\mathrm{M}$ \\
\hline 16 & $\mathrm{M}$ & $\mathrm{H}$ & $\mathrm{L}$ & $\mathrm{M}$ \\
\hline 17 & $\mathrm{M}$ & $\mathrm{H}$ & $\mathrm{M}$ & $\mathrm{M}$ \\
\hline 18 & $\mathrm{M}$ & $\mathrm{H}$ & $\mathrm{H}$ & $\mathrm{H}$ \\
\hline 19 & $\mathrm{H}$ & $\mathrm{L}$ & $\mathrm{L}$ & $\mathrm{L}$ \\
\hline 20 & $\mathrm{H}$ & $\mathrm{L}$ & $\mathrm{M}$ & $\mathrm{M}$ \\
\hline 21 & $\mathrm{H}$ & $\mathrm{L}$ & $\mathrm{S}$ & $\mathrm{M}$ \\
\hline 22 & S & $\mathrm{M}$ & $\mathrm{L}$ & $\mathrm{M}$ \\
\hline 23 & $\mathrm{~S}$ & $\mathrm{M}$ & $\mathrm{M}$ & $\mathrm{M}$ \\
\hline 24 & $\mathrm{~S}$ & $\mathrm{M}$ & $\mathrm{S}$ & $\mathrm{H}$ \\
\hline 25 & $\mathrm{H}$ & $\mathrm{H}$ & $\mathrm{L}$ & $\mathrm{M}$ \\
\hline 26 & $\mathrm{H}$ & $\mathrm{H}$ & $\mathrm{M}$ & $\mathrm{H}$ \\
\hline 27 & $\mathrm{H}$ & $\mathrm{H}$ & $\mathrm{H}$ & $\mathrm{H}$ \\
\hline \multicolumn{5}{|c|}{$\mathrm{L}=$ Low, $\mathrm{M}=$ Medium, $\mathrm{H}=$ High } \\
\hline
\end{tabular}


Figure 3 represents the comparison of two input variables Emergency Professional Onsite \& Local Supporting Agent and Internal Management \& Decision Support Makers if the Probability value of Emergency Professional Onsite \& Local Supporting Agent up to $45 \%$ and Internal Management \& Decision Support Makers is $1 \%$ then the Disaster Management is $0 \%$. By gradually increasing Internal Management \& Decision Support Makers up to $50 \%$ and Emergency Professional Onsite \& Local Supporting Agents 45\% then the Disaster
Management is also increasing $\mathrm{p}$ to $50 \%$.

After increasing both variable probability from $50 \%$ to $100 \%$ the probability of Disaster Management is gradually increasing from $50 \%$ to $90 \%$. Figure 4 shows the comparison between Emergency Professional Onsite \& Local Supporting Agent and Information Resources by increasing both variable probability the Disaster Management is also increasing.

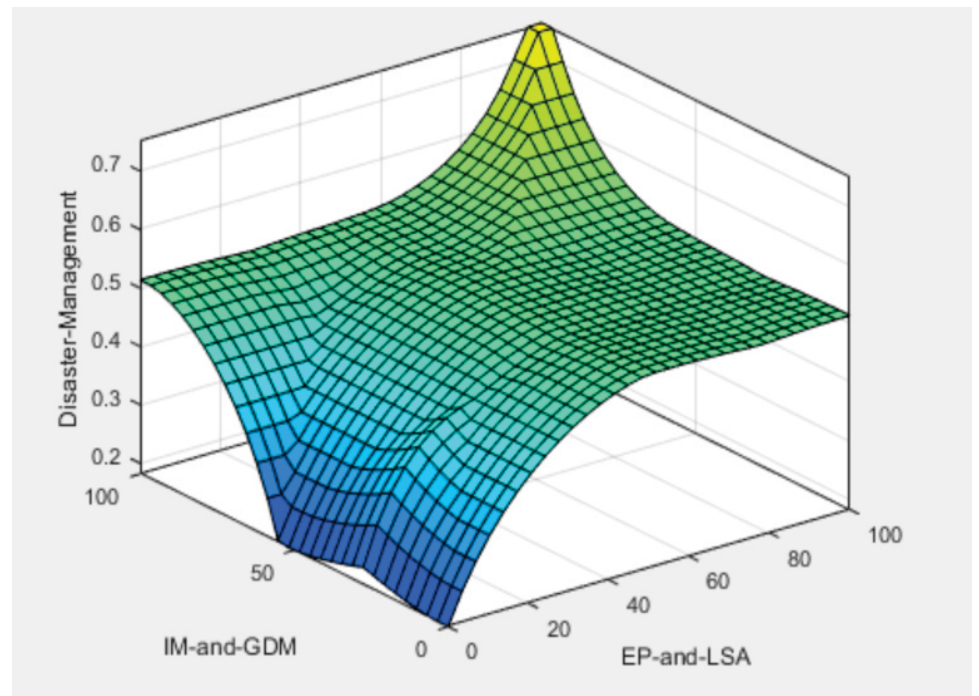

Figure 3: Rule Surface for IM\&GDM and EP\&LSA

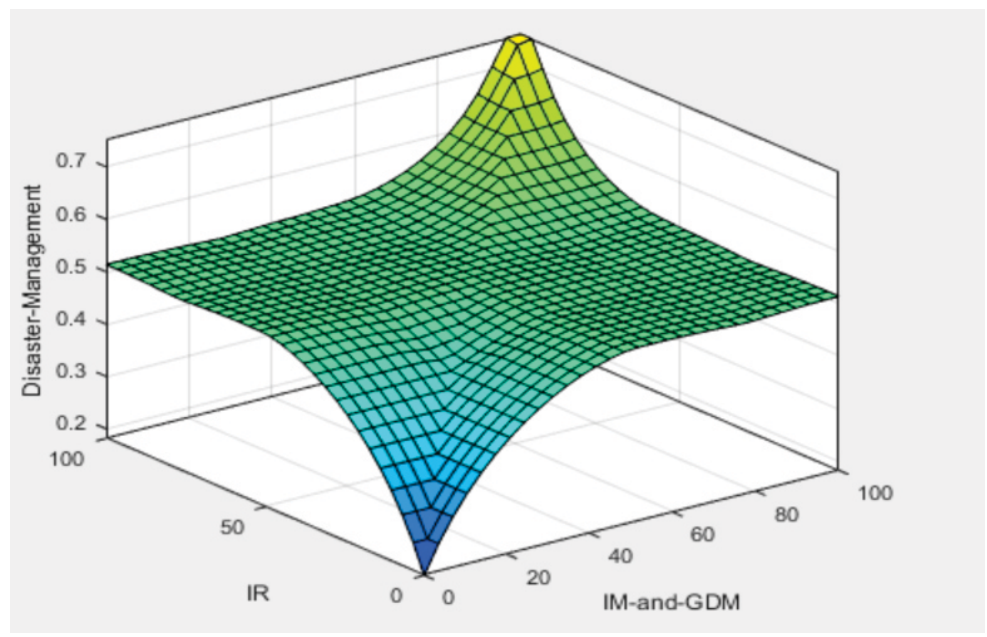

Figure 4: Rule Surface for IR and IM\&GDM 
Figure 5a shows that if the Internal Management \& Decision Support Makers is 0.238, Emergency Professional Onsite \& Local Supporting Agent is 0.47 and Information Resources is 0.27 then the Disaster Management is 0.25 which is Low.

Figure 5b shows that if the Internal Management \& Decision Support Makers is 0.238, Emergency Professional Onsite \& Local
Supporting Agent is 0.7 and Information Resources is 0.49 then the Disaster Management is 0.49 which is Medium.

Figure 5c shows that if the Internal Management \& Decision Support Makers is 0.49, Emergency Professional Onsite \& Local Supporting Agent is 0.75 and Information Resources is 0.77 then the Disaster Management is 0.74 which is high.

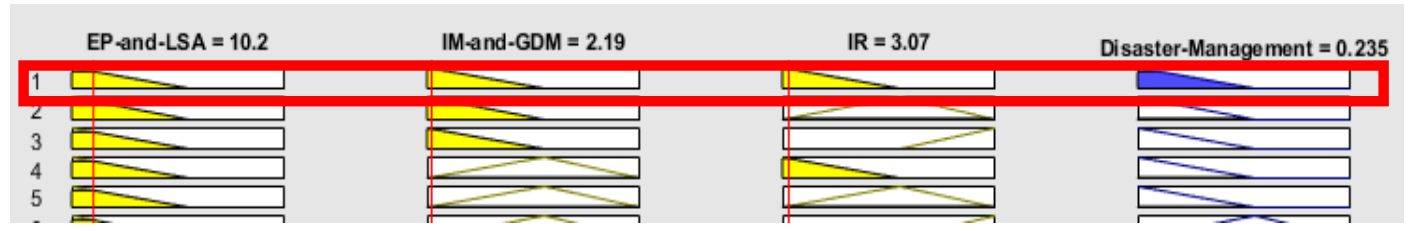

Figure:5aLookup diagram for Low Disaster Management

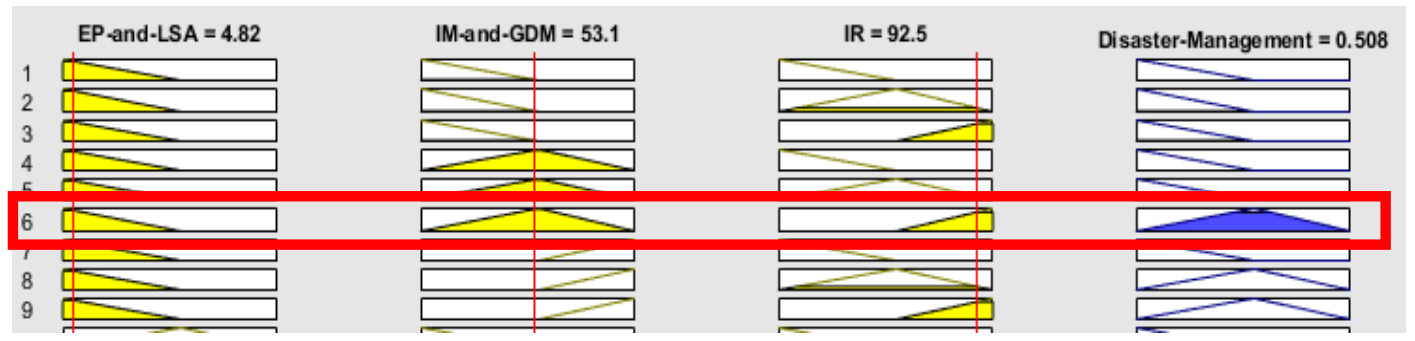

Figure:5b Lookup diagram for Medium Disaster Management

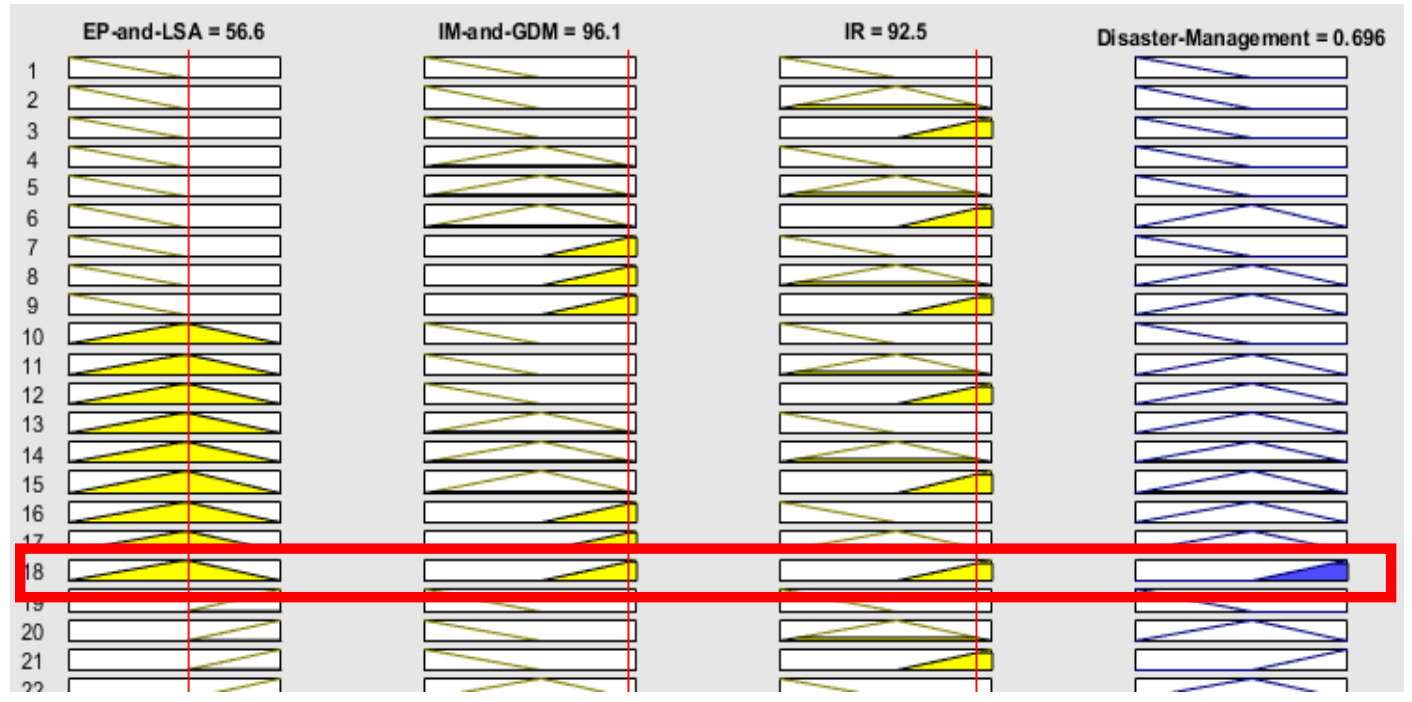

Figure:5c Lookup diagram for High Disaster Management 